\title{
Inner Supporting Application Study of Piling Support in Deep Muddy Stratum Pit
}

\author{
Ma Hui ${ }^{1, a}$ \\ ${ }^{1}$ China Railway Erju Co.Ltd, Chengdu 10086, China \\ aerjumahui@sohu.com
}

Keywords: Muddy Stratum; Underground Structures; Deep Pit; Inner Supporting of Piling Support; Monitoring Measurement.

\begin{abstract}
The support scheme of inner supporting of piling support is adopted for the deep pit engineering of the access of an underground garage located in muddy stratum of Xiamen, under the circumstance of the excavation depth, area, soil layer and surrounding environment of the foundation pit. The monitoring result shows that the inner supporting of piling support better assures the excavation and construction of underground structure smoothly, which does not have adverse effect on the normal use of surrounding environment and achieves better economic and project benefit. Inner supporting of piling support technique is of certain reference value to the construction of foundation pit in soft layer.
\end{abstract}

\section{Introduction}

Nowadays, the depth of foundation engineering becomes deeper, and the area becomes bigger as the development of urban construction and the advancement of old city renovation, and the construction of foundation engineering is often in the dense building group. There are some permanent constructions and public utility, which should be protected because of the small space of construction plant. So the deformation during construction of foundation is strictly controlled [1]. Especially in the southeastern coastal areas, there are some complex situations in the excavation of foundation engineering, such as silty ground, high water level and so on. So some disasters easily occur due to the failed retaining and protecting, such as soil surface slippage, failure of foundation, the change of pile body's position, bottom heave, serious leakage of supporting structure, flowing soil and so on , which might influence the safety of surrounding building, subsurface structure and underground utilities[2]. Pointed to the problem above, the foundation engineering in the soft soil area often adopts bored pile, steel sheet pile, SMW pile, diaphragm wall and other support systems to as the enclosure system of foundation engineering, and the cast-place reinforced concrete or shape steel should be installed to horizontal support for foundation engineering. The arrangement forms of support system with the features of clear force-bearing and safe and reliable, has rectangular type to support system, vertical symmetrical support system, angle support system and truss support system[3]. But the stability of support system is influenced by the length of support system, and it is not ideal in terms of economy. And the dense support arrangement can influence the excavation and transportation of earthwork, which might lead to the low-level efficiency of earth cutting. If the supporting of internal piles was used in row, which has the features of reasonable force, safe and reliable supporting system, effective use of construction space, small quantities of structure and so on, the progress of works could effective quicken. And the arrangement of internal supporting should be simple as much as possible to make the earth cutting used machine and construction of underground structure become convenient. So the supporting of internal piles in row is used in the Jiuzhou building and China Shangdu, which gets the good effect and saves time and cost of construction. The inner supporting of piling support is adopted for the deep pit engineering of the access of a underground garage located in Xiamen, which as a sample to do the analysis of deformation and stress in this paper. And the feature of application of inner supporting of piling support should also get evaluation. 


\section{Project profile}

The project is the foundation engineering of the access of an underground garage located in the Xiamen, and the length of access is $270.679 \mathrm{~m}$, the length of two holes tunnel is $48.843 \mathrm{~m}$, the length of single bore tunnel is $64.013 \mathrm{~m}$, and the length of channels of $U$ shape is $42 \mathrm{~m}$. The clear width of single bore tunnel, adopting the construction of open cut, is $10.1 \mathrm{~m}$, and the section size is $11.3 \times 5.43 \mathrm{~m}$, and its stake mark is $\mathrm{A} 0+105 \sim \mathrm{A} 0+169.013$ :The construction, which is in the part combined with the sidewalk, adopts the section of two holes tunnel. and the section size is $16.9 \times 5.43 \mathrm{~m}$. and its stake mark is $\mathrm{A} 0+169.013 \sim \mathrm{A} 0+217.856$, and the method of open cut is used in the stake mark of $\mathrm{A} 0+169.013 \sim \mathrm{A} 0+179.013$ and $\mathrm{A} 0+201.856 \sim \mathrm{A} 0+209.856: \mathrm{In}$ the section of $\mathrm{A} 0+179.013 \sim$ $\mathrm{A} 0+201.856$, there pass through a vital communication line with the length of $22.843 \mathrm{~m}$, adopting the method of underground excavation: the section of $\mathrm{A} 0+209.856 \sim \mathrm{A} 0+217.856$, which is the joint combined with drainage culvert, adopts drainage culvert first and then underground excavation to proceed construction. The arrangement plan of foundation pit and monitoring point is seen as the fig.1.

The supporting way proposed in this construction is inner supporting of piling support with consideration of excavation depths, area, soil, the surrounding environment and other actual situation. The maximum excavation depth of this foundation pit is about $8 \mathrm{~m}$, and the maximum excavation width is $19.5 \mathrm{~m}$. the bored pile is adopted to support on the both sides of foundation pit, and the waterproof curtain, which is made by high pressure sprinkling stake, is used in the middle of the every two piles. The steel tube is installed on the top of both sides supporting piles to as lateral support and deep mixing method can be used to precede soft soil improvement in the foundation pit. Based on the construction technical criterion of building foundation pit, the safety grade of this foundation pit is first level, and the important factor is 1.1

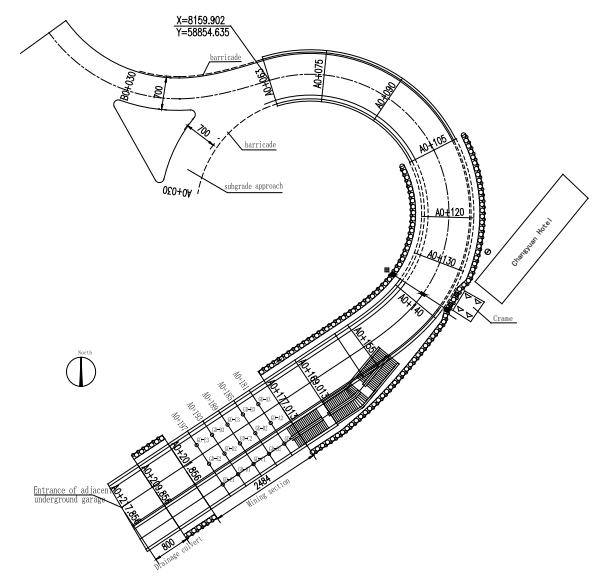

Fig.1. The arrangement plan of foundation pit and monitoring point

According to the geological exploration and drilling, from the top of foundation soil to the bottom of foundation soil, the foundation soil of ground proposed concludes plain fill, silt, saturated silty soft clay, coarse sand consists of boulder clay, residual sandy sticky clay and weathered totally granite. the plain fill and silt $\sim$ saturated silty soft clay are all the soft soil layer, and the range of thickness of plain fill is from $1.8 \mathrm{~m}$ to $7.5 \mathrm{~m}$, and the range of density of plain fill is from slightly less dense to medium density. The density of plain fill usually is better except some positions, and the overall plain fill has the feature of low strength, medium compressibility and bad homogeneity. The range of thickness of silt $\sim$ saturated silty soft clay is from $7.3 \mathrm{~m}$ to $15.0 \mathrm{~m}$, and the range of density of silt $\sim$ saturated silty soft clay from the plastic-flow to soft-plastic, and the silt $\sim$ saturated silty soft clay has the features of low strength, high compressibility and bad engineering performance. The construction of channel is mainly located in the soft soil layer. 


\section{The design and construction of foundation pit supporting}

The supporting piles on both sides of foundation pit.The supporting piles on both sides of foundation pit in the closed frame tunnel adopts bored pile $(\Phi 1000 \mathrm{~mm} @ 1300 \mathrm{~mm})$, and the range of length of piles is from $10.3 \mathrm{~m}$ to $14.3 \mathrm{~m}$. The concrete used in the piles adopts underwater concrete, and the half of pile is embedded in the soil with the remaining be in the air. The top beam $(1000 \mathrm{~mm} \times 750 \mathrm{~mm})$, whose concrete label is C30,is installed on the top of piles. The position and move towards of existing underground pipelines should be curtained before construction, and artificial drilling can be adopted below underground about $3 \mathrm{~m}$ before using construction of drilling for fear of breaking the underground pipelines. At the same time, the drilling machine can be reasonable installed according to the design drawings and engineering geological investigation reports. Construction can start after the ground becomes smooth near the position of piles and the slurry pool can be all planned. In order to prevent the collapse of pile hole because of the closer distance of two piles or the shorter spacing of time during construction, the method of jump-hole should be constructed in the construction of piles. The detailed design is seen as the fig.2, and the site operation is seen as the fig.2.

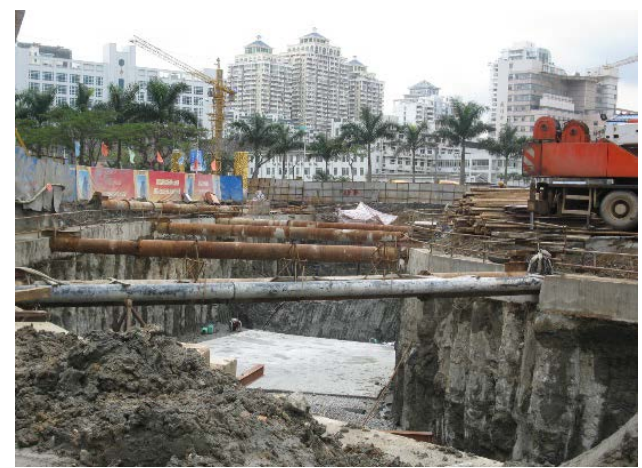

Fig.2 On-site photos of supporting structure

The waterproof curtain between piles. High pressure jet grouting piles function as the waterproof curtain in combined framework tunnel. The water level outside of foundation pit can keep stable with installing waterproof curtain, which can avoid the bad influence on the environment because of the settlement of foundation soil reduced by the decline of a water table in foundation pit. The range of length of high pressure jet grouting is from $3 \mathrm{~m}$ to $8.15 \mathrm{~m}$, and the diameter of high pressure jet grouting is $600 \mathrm{~mm}$ with spacing of $1300 \mathrm{~mm}$. The construction method of high pressure jet grouting is double pipes method with the strength of 20MPa of grouting pressure and with the water-cement ratio of 1:1 of cement grout. The cement content is $500 \mathrm{~kg}$ per meter. The construction can start after the strength of high pressure jet grouting come to $70 \%$ of design strength of itself.

The settlement of soft foundation and drainage facility. The cement mixing pile can be used to reinforce sludge formation and also can be as waterproof curtain. There are 2250 cement piles used in the construction with average length of $12.75 \mathrm{~m}$, and the arrangement form of cement pile is quincunx with the spacing of $900 \mathrm{~mm}$. The pile body should be asked to pass through soft clay to get into $2 \mathrm{~m}$ of bearing stratum (clay stratum or coarse sand consists of boulder clay). There are some factors to influence the construction quantity of cement mixing pile, such as cement content, hoisting speed of drilling machine, homogeneity and continuity of guniting and performance of construction machinery. The drainage outside foundation pit uses temporary drainage ditch to put the surface water into municipal pipeline; and the drainage in foundation pit uses the drainage ditch installed around the bottom of foundation pit with installing collector well per $50 \mathrm{~m}$ to put water into municipal pipeline by using water pump.

The excavation of foundation pit and construction of supporting inside. The excavation of foundation pit main adopts the hydraulic excavator, and using three excavators do the relay excavation on the three steps. The little lateral earthwork can adopt the style of vertical hoisting to out the foundation pit. The order and method of earth excavation should follow the principle of doing excavation after supporting, layered excavation and forbidding over excavation. And earthwork 
should follow the layered, sectionalized and symmetric method to do excavation. Height difference of the excavation face should not be oversize (soft soil not greater than $1 \mathrm{~m}$ ), and length of sectioned excavation is about $20 \mathrm{~m}$, and soil pressure difference should be decreased as much as possible to guarantee force equality of supporting structure and to decrease deformation of structure. The last earthwork with the thickness of $30 \mathrm{~cm}$ should be excavated by manual work to forbid over excavation. The steel supporting can be timely installed to keep stability of foundation pit when excavation reaches the designed elevation. The steel tube with the diameter of 600 is installed on the both sides of top of piles to support foundation in the direction of horizon. The thickness of steel tube is $10 \mathrm{~mm}$ with spacing of $5.2 \mathrm{~m}$, and spacing between two piles can be adjusted based on the monitoring of supporting piles. The clearance used for access of machine should be made in advance under supporting in direction of horizon.

The reinforcement measure of tower crane. Tower crane foundation located in the south side of foundation pit is closely near support piles. Tower crane might be in the danger of overturn because of failed supporting. In order to ensure the correct work of tower crane, the settlement of reinforcement must be made. The following is the reinforcement measure: one steel tube can be installed to do supporting where is from excavation of earthwork to top team. Two steel tubes that function as inside supporting can be installed when the strength of top beam reaches the $80 \%$ of designed strength of top team in construction of top beam. And the pre-applied force on the steel tube is $100 \mathrm{KN}$. And the disturbance on pile foundation of tower crane caused by drill hole should be decreased during construction of supporting piles.

\section{The analysis of monitoring results}

The monitoring of settlement around buildings. The start time of settlement monitoring of Tower crane foundation located in the south side of foundation pit is $9 / 12 / 2009$, and the settlement monitoring is ended when the backfill of foundation reaches level of 0.000 . The fig. 3 is the Graph of tower crane settlements vs time. From the graph, the following information can be got: During the construction of bored pile and high pressure jet grouting, the largest settlement, which occurs at the point of $T-3$, is less than $1 \mathrm{~mm}$, because the foundation of tower crane passes through the bearing stratum of granite though deep soil is disturbed near tower crane. During construction of foundation pit, the largest settlement, which occurs at the point of T-2 near foundation pit, is less than $2 \mathrm{~mm}$, because one increased steel tube used for inside supporting, is installed in the foundation pit near tower crane. So the reinforcement measure of tower crane is proper, and the increased steel tube supporting controls the deformation of foundation pit.

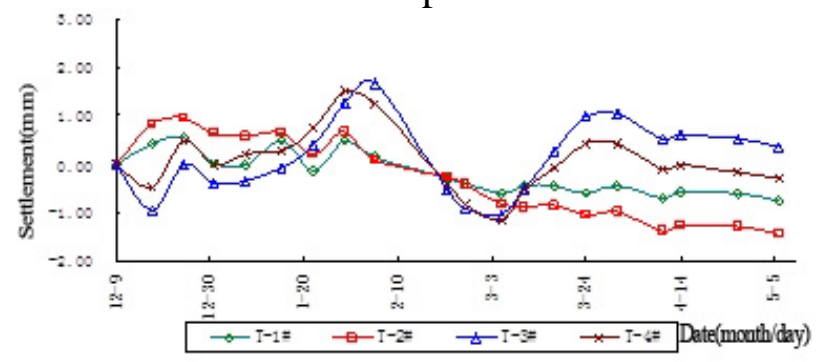

Fig.3 Graph of tower crane settlements vs. time

Horizontal displacement monitoring of top of Support pile. The measure point of horizontal displacement monitoring of top of support pile is installed on the top beam, adopting the method of free installed station used total station makes the monitoring for horizontal displacement of top of support pile[6]. The start time of monitoring of horizontal displacement of top of support pile is $3 / 3 / 2010$, and the displacement of monitoring is ended when the backfill of foundation reaches level of 0.000 . The fig. 4 is Graph of horizontal displacement vs. time of pile cap of retaining piles. From the graph, the following information can be got: the horizontal displacement of top of pile increases fast in the excavation of foundation pit, but the increase of displacement becomes gradually slow as the finish of excavation of supporting; displacement becomes stable when the size of displacement 
increases to about $14 \mathrm{~mm}$, which indicates that supporting of foundation designs reasonable with adopting effective measures and safe supporting structures. It is found that the displacement of measure points (zd4 and zd5) are larger than others during monitoring courses, perhaps because lots of building materials and equipments accumulate near slope of foundation pit to make rapid increase of load during excavation of foundation pit. And the other reason is that foundation pit not make timely backfill in order to leave enough work space for underground excavation of channel near the section (from A0+169.013 to A0+179.013). The horizontal displacement of measure point becomes stable after the finish of construction of framework tunnel and the backfill of foundation pit.

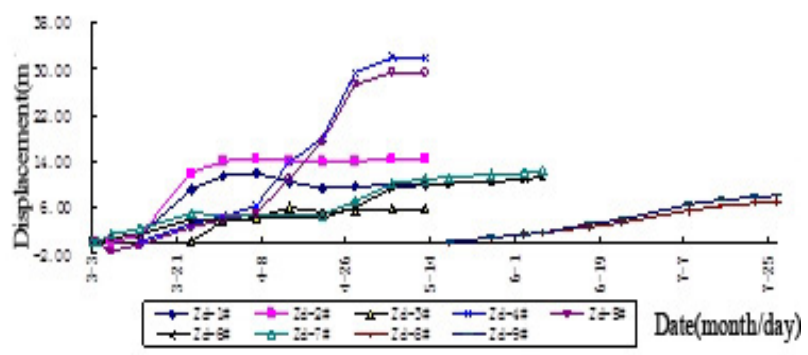

Fig.4.Graph of horizontal displacement vs. time of pile cap of retaining piles

Horizontal displacement monitoring of supporting structure and deeper soil layer.The gradiograph can be used to conduct monitoring for horizontal displacement monitoring of deeper soil layer and pile deformation. The inclinometer used in monitoring of pile deformation can adopt colligation method to be imbedded in supporting piles. The inclinometer used in monitoring of deeper soil layer can adopt ring-hole method to be imbedded in selected location. The monitoring of deformation of supporting structure starts at the time of 3/7/2010, and the monitoring of horizontal displacement of deeper soil layer starts at the time of 16/4/2010 ends when the backfill of foundation reaches level of 0.000 . And the method of choosing the representative measure point of pile deformation (CX-1\#) and horizontal displacement of soils (CX-8\#) can be used to conduct analysis. The fig.5 is Graph of horizontal displacement vs time of supporting structure and deeper soil layer. From the graph, the following information can be got: the deeper horizontal displacement of CX-1\# and CX-8\# gradually increase during the excavation of foundation pit. But the rate of deformation slows down rapidly and becomes stable after construction of spacer, and the deformation main happens during the excavation of earthwork. The deformation of two measure points all reach the maximum value after finish of backfill. And the respective accumulative deformation of two measure points is $8.59 \mathrm{~mm}$ and $8.22 \mathrm{~mm}$, which respective happen on the top pile and under the top pile of $4 \mathrm{~m}$. Because tower crane foundation is closely to pile measured by the measure point of CX-1 and the foundation platform and the supporting structure illustrated the formation as a whole , the horizontal stiffness of supporting pile get the bigger improvement, which lead to the difference between this pile and soils of CX-8\# in terms of deformation curve. 

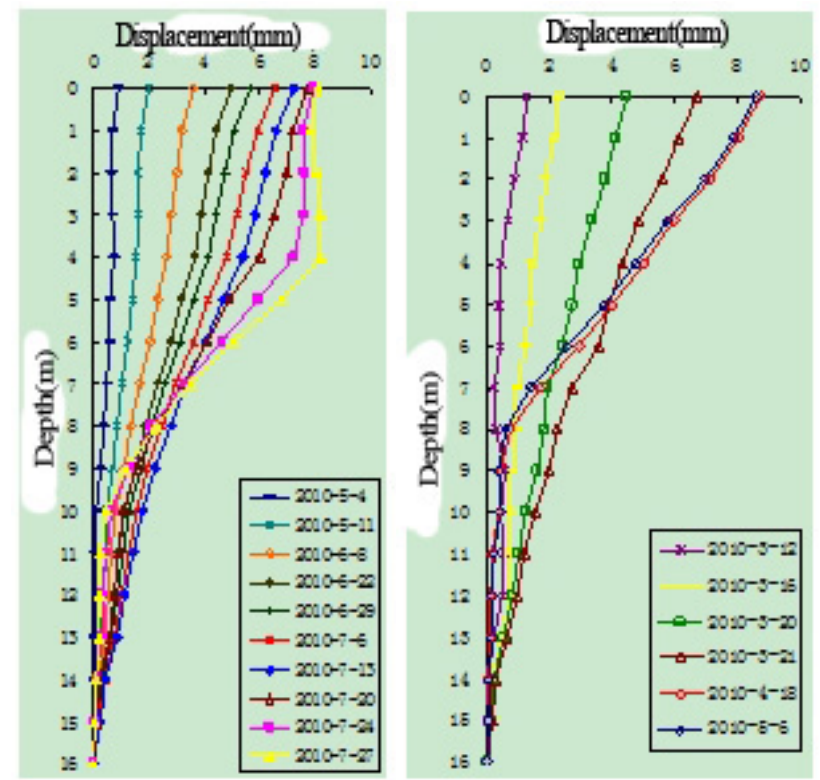

a) The displacement of CX-1\# used inclinometer b) The displacement of CX-8\# used inclinometer

Fig.5 Graph of horizontal displacement vs. time of supporting structure and deeper soil layer

The monitoring of axial force of the supports. The method is that surface strain gage is welded in the $1 / 3$ of length of steel braces, which can be used to conduct monitoring of axial force of the supports. The monitoring of axial force of the supports starts at the time of 3/7/2010 and ends when the backfill of foundation reach level of 0.000 . The fig. 6 shows the detailed changing process of axial force of the supports with the change of time. From the viewpoint of deformation trend of axial force curve, the value of axial force of the supports increases as the increase of depth of excavation depth. And the value of axial force of the supports decreases or becomes stable after the concreting of structure on the bottom of foundation pit and the backfill of foundation when excavation of earthwork reaches the bottom of foundation pit. The axial force of the supports at the measure point of ZC-1\# is bigger than other points compared with other position in terms of axial force of the supports. Because overall deformation and relative compression of supporting is bigger at the point of ZC-1\#, so the axial force is really bigger than others. The respective accumulated maximum axial force of the four points is $1433.21 \mathrm{kN}, 1136.92 \mathrm{kN}, 1154.87 \mathrm{kN}$ and $573.24 \mathrm{kN}$. And the vast majority of value exceeds prewarning value, but the foundation pit not has danger and the axial force becomes stable after the installment of steel supporting. The area has plenty of rainfall and the time of excavation of foundation pit is in the rain season, so the supporting piles of foundation pit must face the danger made by lateral water pressure, which lead to increase of axial force of supports to a certain degree. But the whole foundation pit tends to be safe.

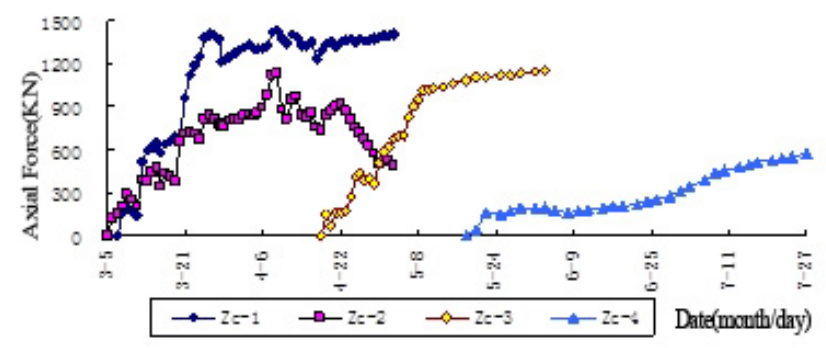

Fig.6 Graph of strut axial forces vs.time

The monitoring of groundwater level outside foundation pit. The water level indicator is adopted to monitor the groundwater level around foundation pit. The fig.7 shows water level variation vs time. The monitoring results show that the groundwater level changes not big as the increase of depth of excavation of foundation pit. And the amplitude variation of water level of most measure points are in the range of $1 \mathrm{~m}$, which illustrates that the waterproof curtain made by high pressure jet grouting pile on the side of foundation pit works good and the phenomenon of leakage not happen in the excavation of side of foundation pit. The big change of groundwater level can be influenced by 
rainfall, because the rainwater infiltrated the ground can make the water level improve. And the groundwater level can almost recover the original level when the weather becomes fine.

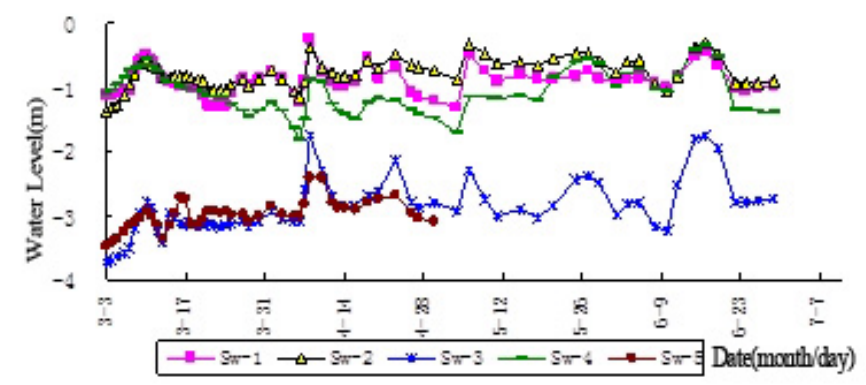

Fig.7 Graph of water level variation vs. time

\section{Conclusions}

According to the monitoring result of foundation pit engineering of the access of a underground garage located in muddy stratum of Xiamen, though there exists some danger in construction of foundation pit in dense buildings, the danger can be avoid with good method of design and construction to guarantee safe construction. The following main conclusions can be got based on the research contents above.

(1) The foundation pit located in the layer of soft muddy soil adopts inner supporting of piling support, which has the feature of big support stiffness and high effect and quality of construction. So it can solve the problems of quality and deformation caused by soil pressure, and also can effective use construction space in construction plant to get higher social benefit and economic benefit.

(2) The horizontal displacement of supporting structure and deeper soils increase faster during the excavation of foundation pit. But horizontal displacement can be controlled after timely making steel supporting and spacer, so the excavation assort with support system can be realized.

(3) From the point of monitoring results in the excavation, the increase of axial force of support is asymmetrical especially the third excavation. The axial force in excavation area increase bigger, and the axial force in other areas also increase, which illustrates that the space work of steel support structure works well, and the structure stress tend to reasonable under the help of compatibility of deformation of steel support.

\section{References}

[1] Zhao Xihong. Theory and Practice of Excavation Engineering.Beijing,China Communications Press (2005).

[2] Huang Weidong. Example on Support and Defense of Deep Foundation Pit for Soft Layer in South Fujian Foreland,Fujian Architectural65 (1999)36-38

[3] Xiamen Construction Committee. Supporting technique of Deep Foundation pit -Examples of Bracing Engineering of Deep Foundation Pit in Xiamen.Beijing:China Water Power Press(1999)2-6

[4] Xiamen Huayan Reconnaissance \& Design CO.; LTD. Geological investigation report for Jiaheyuan underground parking project. Xiamen, Xiamen Huayan Reconnaissance \& Design CO.; LTD. 2007

[5] Lin Zegeng. Horizontal Displacemen of Foundation Pit Monitoring in Freedom Station.Guangzhou Architectural 26(2003) 35-37 